\title{
Conditional overexpression of TGF- $\beta 1$ disrupts mouse salivary gland development and function
}

\author{
Bradford E Hall ${ }^{1}$, Changyu Zheng ${ }^{2}$, William D Swaim ${ }^{2}$, Andrew Cho ${ }^{3}$, Chandrasekharam N Nagineni ${ }^{4}$, \\ Michael A Eckhaus ${ }^{5}$, Kathleen C Flanders ${ }^{6}$, Indu S Ambudkar ${ }^{2}$, Bruce J Baum ${ }^{2}$ and Ashok B Kulkarni ${ }^{1}$
}

Transforming growth factor- $\beta$ (TGF- $\beta$ ) signaling is known to affect salivary gland physiology by influencing branching morphogenesis, regulating ECM deposition, and controlling immune homeostasis. To study the role of TGF- $\beta 1$ in the salivary gland, we created a transgenic mouse $\left(\beta 1^{\text {glo }}\right)$ that conditionally overexpresses active TGF- $\beta 1$ upon genomic recombination by Cre recombinase. $\beta 1^{\text {glo }}$ mice were bred with an MMTV (mouse mammary tumor virus)-Cre (MC) transgenic line that expresses the Cre recombinase predominantly in the secretory cells of both the mammary and salivary glands. Although most of the double positive $\left(\beta 1^{\text {glo }} / \mathrm{MC}\right)$ pups die either in utero or just after birth, clear defects in salivary gland morphogenesis such as reduced branching and increased mesenchyme could be seen. Those $\beta 1^{\text {glo }} / \mathrm{MC}$ mice that survived into adulthood, however, had hyposalivation due to salivary gland fibrosis and acinar atrophy. Increased TGF- $\beta$ signaling was observed in the salivary gland with elevated phosphorylation of Smad 2 and concomitant increase in ECM deposition. In particular, aberrant TGF- $\beta 1$ overexpression caused salivary gland hypofunction in this mouse model because of the replacement of normal glandular parenchyma with interstitial fibrous tissue. These results further implicate TGF- $\beta$ in pathological cases of salivary gland inflammation and fibrosis that occur with chronic infections in the glands or with the autoimmune disease, Sjögren's syndrome, or with radiation therapy given to head-and-neck cancer patients.

Laboratory Investigation (2010) 90, 543-555; doi:10.1038/labinvest.2010.5; published online 8 February 2010

KEYWORDS: transforming growth factor- $\beta$; fibrosis; salivary glands; saliva

Transforming growth factor- $\beta 1$ (TGF- $\beta 1$ ) is a multifunctional cytokine that influences salivary gland development and homeostasis. In particular, TGF- $\beta 1$ is known to regulate ECM deposition not only by inducing biosynthesis of collagens and fibronectin, ${ }^{1,2}$ but also by promoting the expression of protease inhibitors. Furthermore, TGF- $\beta 1$ is able to encourage epithelial-mesenchymal transition in some cells that can result in more ECM-producing myofibroblasts. ${ }^{3,4}$ Tissue damage to the salivary glands from inflammation or radiation exposure can result in reparative TGF- $\beta$-induced ECM production. ECM deposition by TGF- $\beta 1$ shapes epithelial-mesenchymal interactions throughout salivary gland organogenesis as well. Along with regulating mesenchymal production of ECM, TGF- $\beta 1$ can also influence salivary gland development by controlling cellular growth and differentiation. Secretion of TGF- $\beta 1$ inhibits the proliferation of epithelial cells by downregulating c-myc while simultaneously increasing the expression of cyclin-dependent kinase (cdk) inhibitors such as p15, p21, and p27.5 Lastly, TGF- $\beta 1$ affects salivary gland physiology by regulating angiogenesis $^{6}$ and by suppressing inflammation. ${ }^{7}$

TGF- $\beta 1$ and its other two mammalian isoforms, TGF- $\beta 2$ and TGF- $\beta 3$, are all expressed in the salivary gland during development, which suggests an important role for this cytokine in glandular organogenesis. ${ }^{8}$ Specifically, expression of TGF- $\beta 1$ seems to coincide with salivary gland differentiation. ${ }^{9}$ TGF- $\beta 1$ is originally detected in both the epithelium and the mesenchyme during the initial bud stage, but becomes immunolocalized to only the branching epithelia later in development. ${ }^{8}$ In a 14.5 day post coitum mouse

\footnotetext{
${ }^{1}$ Functional Genomics Section, Laboratory of Cell and Developmental Biology, NIH, Bethesda, MD, USA; ${ }^{2}$ Molecular Physiology and Therapeutics Branch, Bethesda, MD, USA; ${ }^{3}$ Gene Targeting Facility, National Institute of Dental and Craniofacial Research, Bethesda, MD, USA; ${ }^{4}$ Laboratory of Immunology, National Eye Institute, Bethesda, MD, USA; ${ }^{5}$ Diagnostic and Research Service Branch, Division of Veterinary Resources, Office of Research Services, Bethesda, MD, USA and ${ }^{6}$ Laboratory of Cancer Biology and Genetics, National Cancer Institute, National Institutes of Health, Bethesda, MD, USA

Correspondence: Dr AB Kulkarni, PhD, Functional Genomics Section, Laboratory of Cell and Developmental Biology, National Institute of Dental and Craniofacial Research, NIH, 30 Convent Drive, MSC\# 4395, Bethesda, MD 20892, USA.
}

E-mail: ak40m@nih.gov

Received 24 August 2009; revised 16 November 2009; accepted 24 November 2009 
embryo, TGF- $\beta 1$ mRNA expression is localized in the epithelial end buds, sites of active branching in the developing salivary gland. ${ }^{10}$ During this stage of development, TGF- $\beta 1$ may act in a paracrine manner on the mesenchyme and an autocrine manner on epithelial cell growth. Even though TGF- $\beta 1$ mRNA is localized at sites of active branching, exogenous TGF- $\beta 1$ in salivary gland cultures, which mimics overexpression, inhibits branching morphogenesis. ${ }^{11}$ Epithelial growth is disrupted and the ducts appear elongated. After glandular development, TGF- $\beta 1$ expression, however, is localized to the ductal epithelium in the submandibular gland and is absent in the secretory acini. ${ }^{12,13}$

In addition to its role in organogenesis, TGF- $\beta$ also impacts salivary gland physiology by regulating ECM production, particularly in response to tissue injury. Aberrant expression of TGF- $\beta 1$ is often associated with cases of pathological fibrosis. In the salivary gland, fibrosis specifically causes constriction of secretory components, leading to hyposalivation and xerostomia. ${ }^{14}$ Salivary gland fibrosis typically occurs after repeated episodes of inflammation such as after chronic infections in the glands or with the autoimmune disease, Sjögren's syndrome. Fibrosis of the glands also occurs because of tissue damage from radiation, particularly during radiotherapy treatment of head-and-neck cancer. ${ }^{15}$ Interestingly, radiation exposure has been shown to induce TGF- $\beta 1$ expression. ${ }^{16}$

We developed a transgenic mouse that conditionally produces TGF- $\beta 1\left(\beta 1^{\text {glo }}\right)$ to understand the role of TGF- $\beta$ signaling in salivary gland development and homeostasis. The transgene requires Cre-mediated excision of an intervening floxed enhanced green fluorescent protein (EGFP) gene in order for a ubiquitous promoter to transcribe a TGF- $\beta 1$ cDNA. In the transgene, the TGF- $\beta 1$ cDNA is mutated to prevent the assembly of the latent associated peptide, in order to allow direct binding of the secreted ligand onto the cellsurface receptors. We bred these $\beta 1^{\text {glo }}$ mice to a mouse mammary tumor virus (MMTV) Cre (offspring are MC) transgenic line ${ }^{17}$ that strongly expresses the Cre recombinase in both mammary and salivary glands. Broad expression of Cre in these transgenic mice, however, generated a severe phenotype with most of the double-positive $\left(\beta 1^{\text {glo }} / \mathrm{MC}\right)$ pups either dying in utero or within $24 \mathrm{~h}$ after birth. Nonetheless, the effect of TGF- $\beta 1$ on the salivary gland could clearly be seen in the $\beta 1^{\text {glo }} / \mathrm{MC}$ pups with increased mesenchyme and disrupted branching. For those $\beta 1^{\text {glo }} / \mathrm{MC}$ mice that survived into adulthood, the salivary glands were severely fibrotic, with signs of atrophy in both granular convoluted ducts (GCDs) and in the acini, and this was associated with hyposalivation.

\section{MATERIALS AND METHODS}

\section{Construction of pCLE- $\beta 1^{\text {glo }}$ Transgenic Plasmid}

To create a transgenic mouse with recombination-activated TGF- $\beta 1$ expression, we generated the pCLE- $\beta 1^{\text {glo }}$ vector by subcloning an active hemagglutinin (HA) epitope-tagged
TGF- $\beta 1$ cDNA $^{18}$ into pCLE. ${ }^{19}$ The vector pCLE contains a 1.7-kb $\beta$-actin promoter combined with a CMV-IE enhancer (CAG promoter) for ubiquitous expression of the transgene. Downstream from the promoter is a 1-kb EGFP gene that is flanked by loxP sites. A constitutively active $1.2-\mathrm{kb}$ TGF- $\beta 1$ cDNA was subcloned into the pCLE vector after EGFP. The cDNA contains the porcine sequence for TGF- $\beta 1$ from pPK9a, where two cysteines (C223 and C225) were mutated to serines to prevent the latent associated peptide, LAP, from assembling around the mature TGF- $\beta 1$ dimer. $^{20}$ PCR mutagenesis was used to add an HA epitope tag onto the ligand to distinguish exogenous TGF- $\beta 1$ from the endogenous protein. ${ }^{18}$

\section{Cell Culture}

COS7 cells were transfected with pCLE- $\beta 1^{\text {glo }}$ not only to study the efficiency of recombination-mediated expression of TGF- $\beta 1$ from transgene, but also to test the signaling capability of the epitope-tagged protein. COS7 cells were transfected with either pCLE- $\beta 1^{\text {glo }}$ alone or together with the Cre expression vector $\mathrm{pBS} 185^{21}$ using Lipofectamine LTX (Invitrogen). After overnight incubation, the medium was replaced with serum-free Opti-MEM supplemented with MITO plus (BD Biosciences). The supernatants were collected after $48 \mathrm{~h}$ and cells were lysed with T-PER (Pierce) supplemented with a Complete Mini Protease Inhibitor Cocktail (Roche). The COS7 supernatants were treated with $200 \mathrm{mM}$ PMSF (Sigma) and concentrated using an Amicon Ultra centrifugal filter device (Millipore). The supernatants and cell lysates were run on SDS-PAGE gels to test for expression of the epitope-tagged version of TGF- $\beta 1$ from the transgene (see below). To study TGF- $\beta$ signaling, untreated COS7 supernatants from the transfected cells were diluted 1:3 with fresh serum-free medium and plated onto $5 \times 10^{5}$ HepG2 cells in a $6-\mathrm{cm}$ culture dish. The cells were lysed after $30 \mathrm{~min}$ and cell lysates were run on a Western blot gel to determine the level of phosphorylation of Smad2 (see below).

\section{Generation and Genotyping of $\beta 1^{\text {glo }}$ Mice}

After testing the pCLE- $\beta 1^{\text {glo }}$ plasmid in vitro, the transgenic vector was microinjected to generate transgenic mice. The founder lines were genotyped by Southern blot analysis. Tail DNA was digested using NheI, a unique restriction enzyme site within the transgenic vector, and the whole transgene $(4.5 \mathrm{~kb})$ was radiolabeled for use as a probe. $\beta 1^{\text {glo }}$ Mice were then primarily identified through both PCR and with GFP visualization using a Macro Imaging System (Light Tools Research). The mice were genotyped using the following pair of primers: CAGG: $5^{\prime}$-CTCTAGAGCCTCTGCTAACC- $3^{\prime}$ and EGFP: $5^{\prime}$-GGTGCAGATGAACTTCAGGG-3'. To detect recombination within the transgene, a reverse primer in the TGF- $\beta 1$ cDNA was designed ( $\beta$ : $5^{\prime}$-CGCTTTCCACCAT TAGCAC- $\left.3^{\prime}\right)$. Primers were also generated to detect the HA tag (HA For: 5'-CATACGACGTGCCAGACTAC- $3^{\prime}$ and pB1TGA Rev: 5'-TCAGCTGCACTTGCAGGAACG-3') and to 
ensure integration of SV40 pA (pB1-TGA For: 5'-CGT TCCTGCAAGTGCAGCTGA-3' $3^{\prime}$ and SV40 pA: $5^{\prime}$-GATGA GTTTGGACAAACCACAAC- $3^{\prime}$ ). PCR was performed for 40 cycles consisting of $30 \mathrm{~s}$ at $94^{\circ} \mathrm{C}, 30 \mathrm{~s}$ at $57^{\circ} \mathrm{C}$, and $1 \mathrm{~min}$ at $72^{\circ} \mathrm{C}$. The $\beta 1^{\text {glo }}$ mice were bred to MMTV-Cre mice that were generated as previously described. ${ }^{17}$ All experimental studies and procedures were approved by the Animal Care and Use Committee of the National Institute of Dental and Craniofacial Research, NIH.

\section{Saliva Collection}

Saliva production was tested in the resulting adult $\beta 1^{\text {glo }} / \mathrm{MC}$ progeny by using a subcutaneous injection of $0.5 \mathrm{mg} / \mathrm{ml}$ pilocarpine (Sigma) at $0.005 \mathrm{mg}$ per $100 \mathrm{~g}$ body weight to stimulate salivation. The secreted saliva from pilocarpineinjected mice was collected using a micro-hematocrit tube over a period of $30 \mathrm{~min}$.

\section{Histopathology and Immunohistochemistry}

Initial $\beta 1^{\text {glo }} / \mathrm{MC}$ mice were often runted and would typically die perinatally. Newborn mice were killed along with control littermates for pathological study. Sagittal sections were used for histological staining and immunohistochemistry. $\beta 1^{\text {glo }} /$ MC Mice that evaded perinatal lethality were killed between 1 week to10 months of age for analysis. Major organs such as heart, liver, skin, pancreas, kidney, and lung were collected along with glandular tissue (salivary, mammary, lacrimal, and so on) from both wild-type and $\beta 1^{\text {glo }} / \mathrm{MC}$ mice. Tissues were fixed in $10 \%$ buffered formalin and embedded in paraffin. Controls included both $\beta 1^{\text {glo }}$ and wild-type littermates. For histopathology, 5- $\mu \mathrm{m}$ sections were stained with hematoxylin and eosin (H\&E), Masson's trichrome, or mucicarmine. The sections were deparaffinized in xylene, rehydrated with descending grades of ethanol, treated with $3 \%$ hydrogen peroxide for $30 \mathrm{~min}$, blocked for $30 \mathrm{~min}$, and incubated with primary antibody (see below) in a $1 \%$ BSA solution. Next, the sections were treated with the Rabbit on Rodent HRP-Polymer (Biocare) or with a biotinylated secondary antibody (Vector Laboratories) followed by treatment with the Vectastain $A B C$ reagent (Vector Laboratories). Antibody binding was detected using liquid DAB (Biogenex). Immunostaining was performed using the following primary antibodies: 1:100 anti-aquaporin-5 (AQP5; Calbiochem, no. 1078615), 1:400 anti-connective tissue growth factor (CTGF) (Abcam, no. ab6992), 1:500 anti-Smad2, phospho-specific (Ser465/467; Millipore, no. AB3849), 1:500 anti-smoothmuscle actin (Millipore, no. CBL171), and 1:200 anti-TGF- $\beta 1$ (Promega, G1221). Immunohistochemistry for extracellular TGF- $\beta 1$ (anti-CC 1-30) ${ }^{22}$ and immunofluorescence for $\mathrm{AQP}^{23}$ were performed as described previously.

\section{Western Blot and ELISA}

Salivary glands were collected from wild-type and $\beta 1^{\text {glo }} / \mathrm{MC}$ mice and tissue lysates were prepared using T-PER (Pierce) supplemented with a Protease Inhibitor Cocktail (Roche).
Serum from the mice was analyzed by a TGF- $\beta 1$ ELISA (R\&D Systems, no. MB100B). Tissue lysates, cell culture lysates, and cultured supernatants were run on NuPAGE 4-12\%Bis-Tris gels (Invitrogen) using MES buffer. Proteins were transferred onto either an Immobilon- $\mathrm{P}^{\mathrm{SQ}}$ Transfer Membrane (Millipore) or a $0.45-\mu \mathrm{m}$ nitrocellulose membrane (Invitrogen) depending on the molecular weight of the protein. The transferred proteins were incubated overnight at $4^{\circ} \mathrm{C}$ with a primary antibody (see below) in Tris-buffered saline containing 5\% milk and $0.05 \%$ Tween-20. The blots were washed and incubated for $1 \mathrm{~h}$ with HRP-conjugated secondary antibodies (Santa Cruz Biotechnology). Signal was detected using the SuperSignal West Pico chemiluminescent substrate (Pierce). For Western blots, the following antibodies were used: 1:1000 anti-actin (Millipore, no. MAB1501), 1:5000 anti-green fluorescent protein (Roche, no. 11814460001), 1:100 anti-glyceraldehyde-3-phosphate dehydrogenase (Abcam, no.ab9485), 1:50 anti-HA (Santa Cruz Biotechnology, no.sc-805), 1:500 anti-Smad2 (Invitrogen, no.51-1300), and 1:500 anti-Smad2, phospho-specific (Ser465/467; Millipore, no. AB3849).

\section{Preparation of RNA and RT-PCR}

Both RNA and DNA were extracted from wild-type and $\beta 1^{\text {glo }} / \mathrm{MC}$ salivary glands using the TRIzol reagent (Invitrogen) according to the manufacturer's protocol. The extracted RNA was treated with TURBO DNase (Applied Biosystems). Using random primers (Invitrogen), about $500 \mathrm{ng}$ were reverse-transcribed into cDNA using Super Script III reverse transcriptase (Invitrogen). To detect genomic DNA recombination or RNA expression of the HA tag, PCR amplification was performed using the primers listed above (section Generation and Genotyping of $\beta 1^{\text {glo }}$ Mice).

\section{RESULTS}

\section{Generation of $\beta 1^{\text {glo }}$ Mice}

To create a mouse model using conditional overexpression of TGF- $\beta 1$, a transgenic construct, pCLE- $\beta 1^{\text {glo }}$ (Figure 1a), was engineered by subcloning an active $\mathrm{HA}$ epitope-tagged version of the TGF- $\beta 1$ cDNA $^{18}$ into pCLE, ${ }^{19}$ an expression vector amenable to targeted gene activation through sitespecific recombination. ${ }^{24,25}$ The transgenic vector pCLE- $\beta 1^{\text {glo }}$ contains a global promoter for ubiquitous expression of the TGF- $\beta 1$ cDNA, but its transcription is blocked by the placement of an intervening floxed EGFP gene. Using the Cre recombinase, however, the EGFP gene can be excised to juxtapose the promoter and the TGF- $\beta 1$ cDNA together to thereby activate its expression.

To test the transgenic construct for recombination-activated TGF- $\beta 1$ expression, pCLE- $\beta 1^{\text {glo }}$ was transfected into COS7 cells with or without pBS185, ${ }^{21}$ a plasmid containing the gene for Cre recombinase. Whereas cells transfected with pCLE- $\beta 1^{\text {glo }}$ alone had no TGF- $\beta 1$ expression, cells co-transfected with Cre had high levels of TGF- $\beta 1$ secreted into the culture medium, as determined with both anti-TGF- $\beta 1$ and 
anti-HA tag antibodies (Figure 1b). HepG2 cells were then incubated with transfected cell supernatants to determine whether the secreted epitope-tagged TGF- $\beta 1$ protein could activate cell signaling. As seen with phosphorylation of the downstream messenger protein Smad2 (Figure 1c), the secreted epitope-tagged ligand from the dually transfected cells could directly activate the TGF- $\beta$ signaling pathway.

After the transgenic construct was tested, pCLE- $\beta 1^{\text {glo }}$ was microinjected to create the $\beta 1^{\text {glo }}$ founder lines. The founder lines were genotyped by Southern blot analysis (Figure 1d) in which a $4.5-\mathrm{kb}$ band was detected corresponding to the size of the transgene. Integration of the transgene was also confirmed using PCR primers to the floxed EGFP gene, the HAtagged TGF- $\beta 1 \mathrm{cDNA}$, and the flanking $2 \times$ SV $40 \mathrm{pA}$ (data not shown). Three of the $\beta 1^{\text {glo }}$ founder lines were selected for further expansion and all of the lines were bred to maintain a heterozygous state (Figure 1e). All $\beta 1^{\text {glo }}$ mice were healthy and viable, without any toxicity due to transgene integration. In addition, none of the mice showed evidence of any TGF$\beta 1$-induced pathology due to read through transcription past the floxed EGFP attenuator. ${ }^{26}$

\section{Breeding of $\beta 1^{\text {glo }}$ to MMTV-Cre Mice}

$\beta 1^{\text {glo }}$ Mice were bred with an MMTV-Cre line ${ }^{17}$ that strongly, although not uniquely, expressed the Cre recombinase in the salivary glands. The MMTV-LTR used in the Cre transgenic mice predominantly limits its expression to the striated ductal cells of the salivary gland. ${ }^{27,28}$ When $\beta 1^{\text {glo }}$ mice were crossed with the MMTV-Cre line, most pups died in utero, with only about $10 \%$ of the $\beta 1^{\text {glo }} / \mathrm{MC}$-positive pups born
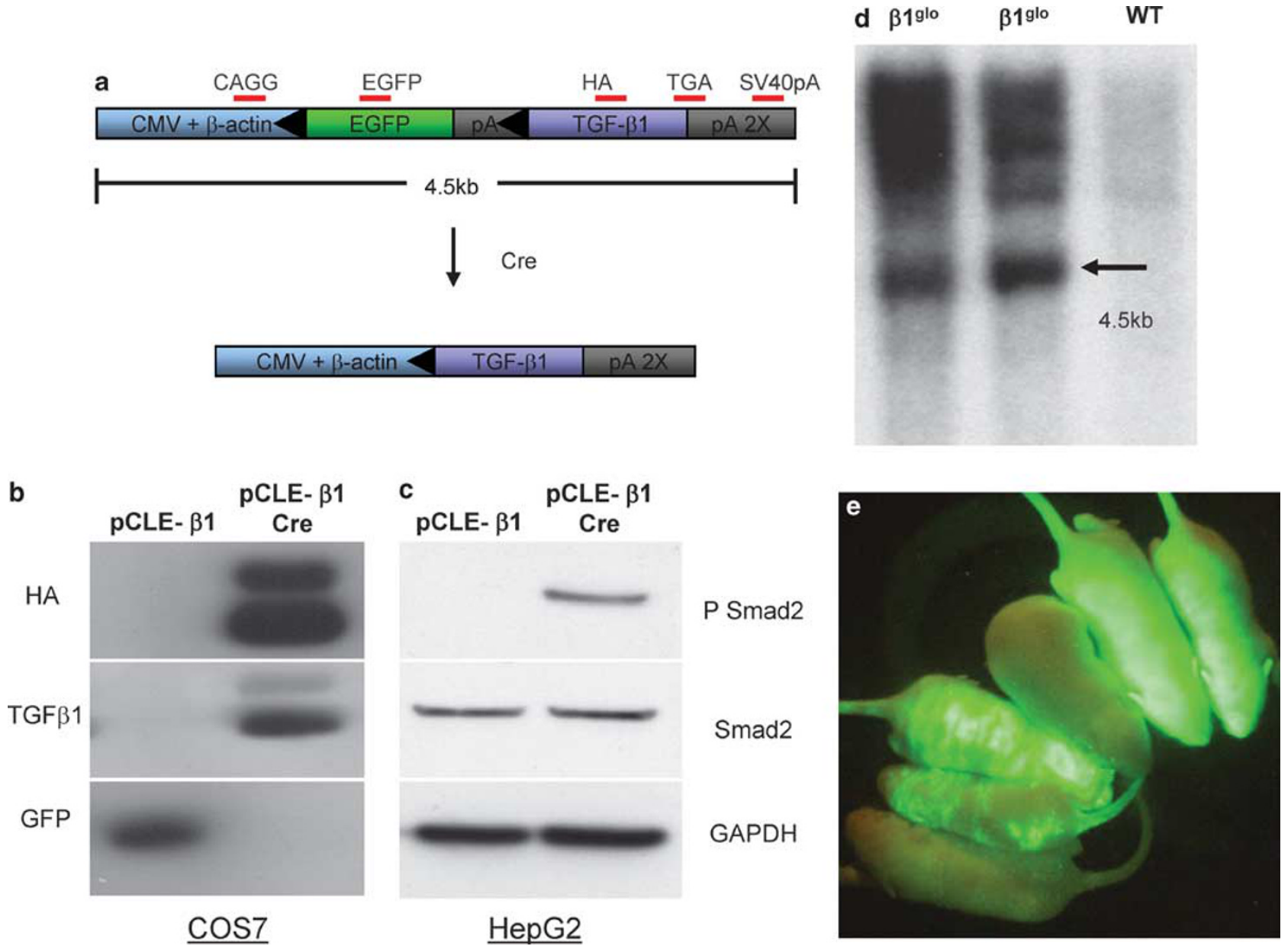

Figure 1 Design and testing of the transgenic construct for generation of $\beta 1^{\text {glo }}$ mice. (a) The schematic of the $\beta 1^{\text {glo }}$ transgene, including location of primers used for genotyping the mice. The vector ( $\mathrm{pCLE}-\beta 1^{\mathrm{glo}}$ ) consists of a $\beta$-actin promoter coupled with a CMV enhancer for ubiquitous expression of the transgene in mice. The gene for EGFP is placed after the promoter and is flanked by loxP sites (indicated with arrowheads). Cre recombination will remove the floxed EGFP gene to align the promoter next to the TGF- $\beta 1$ cDNA. (b) Western blot of COS7 cells transfected with either pCLE- $\beta 1^{\text {glo }}$ alone or in conjunction with a Cre recombinase expression vector. The supernatants were tested with antibodies (indicated to the left) to both TGF- $\beta 1$ and the HA epitope tag, while cell lysates were examined for GFP expression. The secreted HA-tagged TGF- $\beta 1$ ligand can activate TGF- $\beta$ signaling in HepG 2 cells as seen by phosphorylation of Smad2 (right panel; c). (d) Southern blot from $\beta 1^{\text {glo }}$ mice using the whole transgene as a radioactive probe. The arrow indicates the

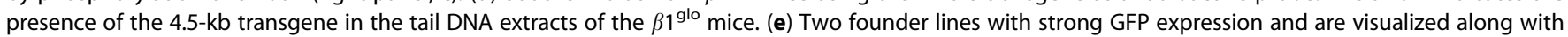
mosaic and non-transgenic mice. 
instead of the $25 \%$ expected. Of the surviving $\beta 1^{\text {glo }} / \mathrm{MC}$ pups, most were runted as compared with their littermates. Initially, for all three transgenic lines tested, these $\beta 1^{\text {glo }} / \mathrm{MC}$ typically would die within $24 \mathrm{~h}$. However, in one of the $\beta 1^{\text {glo }}$ lines, pups were born that survived beyond the perinatal period. These pups could eventually live beyond 1 year of age. The embryonic and early postnatal lethality, however, seen with most of the $\beta 1^{\text {glo }} / \mathrm{MC}$ pups may be due to the broad expression pattern of the Cre recombinase in the MMTV-Cre transgenic line. ${ }^{17}$

Even though the phenotype of the newborn $\beta 1^{\text {glo }} / \mathrm{MC}$ mice was more severe than expected, the role of TGF- $\beta 1$ in salivary gland development could still be studied. In the $\beta 1^{\text {glo }} / \mathrm{MC}$ mice, the submandibular gland was particularly dysplastic due to TGF- $\beta 1$ overexpression (Figure $2 \mathrm{a}$ and $\mathrm{b}$ ). Whereas the submandibular gland was disrupted in the $\beta 1^{\text {glo }} / \mathrm{MC}$ mice, the sublingual gland in one line, at least, was histologically normal (data not shown). This phenotype corresponds to the reported Cre expression pattern in MMTV-Cre mice where little recombination occurs in the sublingual gland. ${ }^{17}$ In the salivary gland of the $\beta 1^{\text {glo }} / \mathrm{MC}$ mice, activation of the TGF- $\beta$ signaling pathway was seen with increased downstream phosphorylation of Smad2 (Figure 2c and d). Branching in the submandibular gland was inhibited and the mesenchyme was increased for all three lines of the $\beta 1^{\text {glo }} / \mathrm{MC}$ mice. The increased mesenchyme in the glands, however, lacked the collagen fibril trichrome staining typical of progressive fibrosis (data not shown). Immunostaining was performed for AQP5, a functional marker of acinar cell polarity, to further examine the disrupted morphology of the salivary gland in the $\beta 1^{\text {glo }} / \mathrm{MC}$ mice. AQP5, a water channel essential for saliva secretion, ${ }^{29,30}$ is localized on the apical membrane of the acinar cells of the control mice as seen with the early terminal-web patterning in the salivary gland. ${ }^{31,32}$ However, $\beta 1^{\text {glo }} / \mathrm{MC}$ mice appeared to have aberrant and mislocalized AQP5 staining, possibly as an indirect consequence of the dyplasitc development induced by TGF- $\beta 1$ overexpression (Figure 2e and f).

Although salivary glands in the newborn pups were dysplastic, no other organs in the mice showed significant developmental defects that could be detected histologically. No difference could be detected in the circulating levels of total TGF- $\beta 1$ between $\beta 1^{\text {glo }} / \mathrm{MC}$ and control pups using ELISAs (data not shown). As all of the major organs such as the heart and lungs showed no noticeable defects, we suspect that rapid perinatal lethality may be due to a skin barrier defect. In particular, Cre-mediated recombination is shown to occur in the skin using the MMTV-Cre mice ${ }^{17,33}$ and a compromised skin barrier may have been a consequence of the antiproliferative effect of TGF- $\beta 1$ on epithelial cells. ${ }^{34}$

\section{Lack of Salivation in Adult $\beta 1^{\text {glo }} / \mathrm{MC}$ Mice}

Although most of the $\beta 1^{\text {glo }} / \mathrm{MC}$ pups born alive die just after birth, one of our $\beta 1^{\text {glo }}$ lines was able to produce offsprings that did not succumb to perinatal lethality $(n=12 ; 7$ males and 5 females were studied between 1 week to 1 year of age). A few individual mice were even capable of living beyond 1 year of age. However, the percentage of pups dying in utero did not change even while more newborn pups survived into adulthood. Adult $\beta 1^{\text {glo }} / \mathrm{MC}$ mice were generally smaller than their littermates with ruffled fur and malformed ears (Figure $3 a$ and $b$ ). This phenotype was likely due to Cre expression in the skin and hair follicles by the MMTV-LTR.

DNA and RNA were extracted from the salivary glands to test for both recombination of the transgene and expression of active TGF- $\beta 1$ in the $\beta 1^{\text {glo }} / \mathrm{MC}$ mice. A $600-\mathrm{bp}$ PCR product was amplified in only the $\beta 1^{\text {glo }} /$ MMTV-Cre mice using primers in the promoter and the TGF- $\beta 1$ cDNA. The size of the PCR product suggests that the 1-kb EGFP gene was excised in the salivary gland by proper Cre-mediated recombination (Figure 3c). RT-PCR was then used with a primer specific to the HA to confirm the expression of the transgenic epitope-tagged TGF- $\beta 1$ in the $\beta 1^{\text {glo }} / \mathrm{MC}$ mice. A 400 -bp PCR product was generated from the salivary glands with primers from the start of the HA tag to the end of the TGF- $\beta 1$ cDNA (Figure $3 c$ ).

In the $\beta 1^{\text {glo }} / \mathrm{MC}$ mice, Cre-mediated TGF- $\beta 1$ expression resulted in profound hyposalivation. Although the cholinergic agonist pilocarpine could stimulate a median of $183 \pm 64 \mathrm{mg}$ of saliva ( $5.0 \pm 1.8 \mathrm{mg}$ saliva/gram of mouse) from the control mice, no measurable amount of salivation could be induced in the $\beta 1^{\text {glo }} / \mathrm{MC}$ mice at 5-10 months of age (Figure 3d). Most animals showed a dry mouth even with administration of pilocarpine. To determine the cause for this diminished salivation, the salivary glands of $\beta 1^{\text {glo }} / \mathrm{MC}$ mice at 1 week to 10 months of age were examined histologically for signs of salivary gland pathology (Figure $3 \mathrm{e}-\mathrm{h}$ ). At all ages, induction of TGF- $\beta 1$ triggered aberrant ECM deposition in the salivary glands of the $\beta 1^{\text {glo }} / \mathrm{MC}$ mice, which led to progressive fibrosis. The growth of the salivary glands appeared to be severely inhibited in the $\beta 1^{\text {glo }} / \mathrm{MC}$ mice between 1 and 4 weeks of age. Even at 1 week of age, initial signs of fibrotic collagen deposition were evident in the submandibular gland along with dilated ducts (Figure $3 e$ and $\mathrm{f}$ ). In older mice (between 5and 10 months of age), TGF- $\beta 1$ overexpression clearly resulted in marked fibrosis and atrophy of the salivary epithelial cells in the submandibular gland (Figure $3 \mathrm{~g}$ and $\mathrm{h}$ ). Inflammatory infiltrates could also be seen in the salivary glands in addition to cellular atrophy. The parotid gland also showed dramatic atrophy in the serous acini with only the ducts still present (data not shown). The sublingual gland, however, was completely unaffected as seen previously in the pups for this line (data not shown). There were no significant pathological lesions seen in most of the other tissues examined. Similar to the observation of Pierce et $a l^{35}$ the mammary gland in one adult female $\beta 1^{\text {glo }} / \mathrm{MC}$ mouse ( 7 months of age) showed no increase in periductal connective tissue, even though active TGF- $\beta 1$ expression was induced using MMTV-Cre. Two male mice, however, had mild tubular atrophy of the testes and one of these had severe 

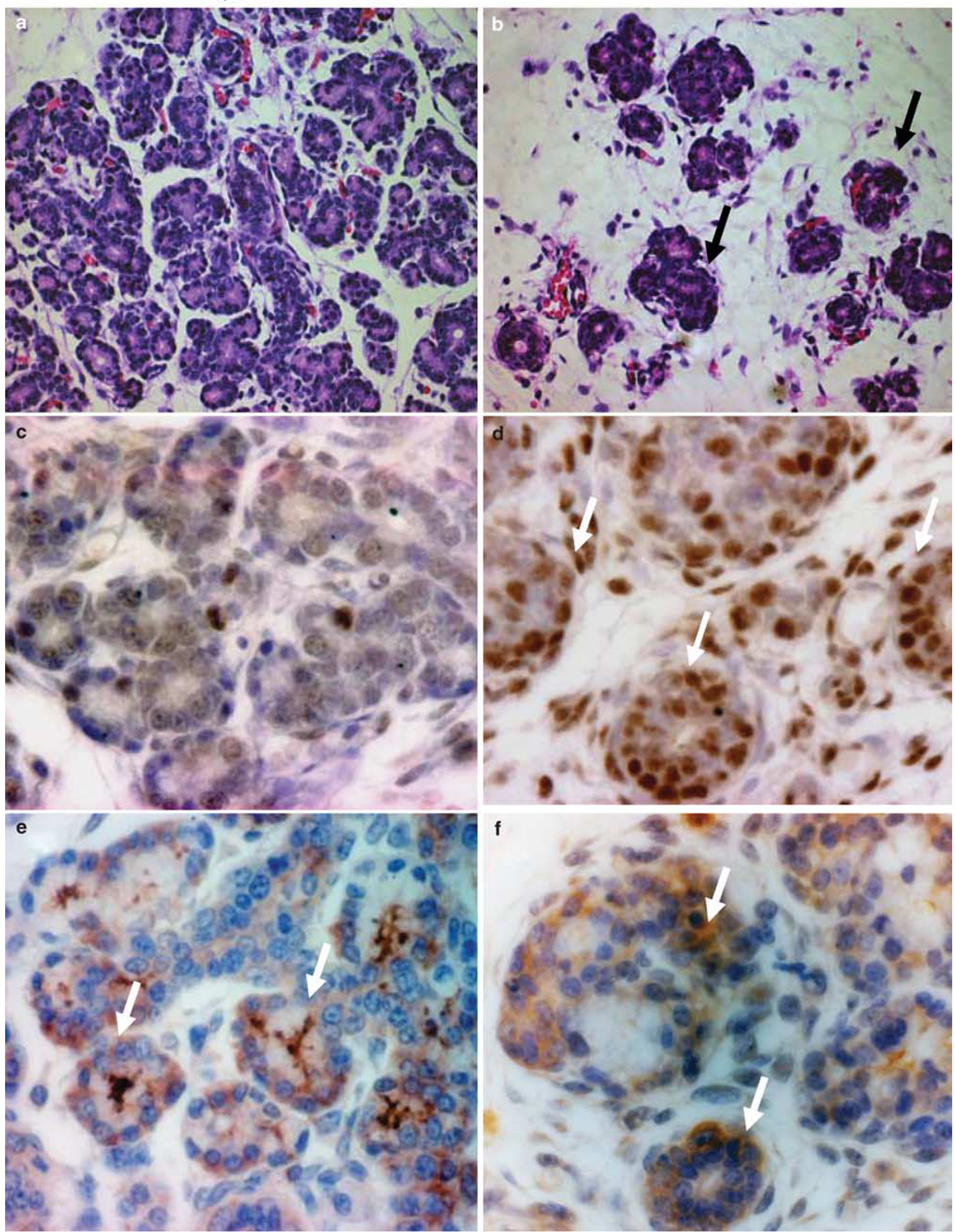
acinar atrophy in the pancreas. No difference could be detected between the $\beta 1^{\text {glo }} / \mathrm{MC}$ mice and the controls regarding the circulating serum levels of total TGF- $\beta 1$ (median $67 \pm 34$ versus $67 \pm 19 \mathrm{ng} / \mathrm{ml}$ ) as well.

\section{Activated TGF- $\beta$ Signaling in $\beta 1^{\text {glo }} / \mathrm{MC}$ Mice}

Cre-mediated TGF- $\beta 1$ expression was further examined in the salivary glands of the $\beta 1^{\text {glo }} / \mathrm{MC}$ mice. Activation of the TGF- $\beta$ signaling pathway by Smad 2 phosphorylation was only detectable in the salivary glands of the $\beta 1^{\text {glo }} / \mathrm{MC}$ mice (Figure 4a). Two bands were seen using anti-phospho-Smad2 (Ser465/467), an antibody that may also cross-react with phosphorylated Smad3 at its equivalent sites (Ser423/425). Immunostaining of the sections showed elevated
TGF- $\beta 1$ expression in the $\beta 1^{\text {glo }} / \mathrm{MC}$ salivary glands as compared with that in the controls (Figure $4 \mathrm{~b}$ and c). TGF- $\beta 1$ staining was mainly detected in the ductal cells and was not seen in the few remaining acinar cells. Increased TGF- $\beta 1$ expression was additionally confirmed using an antibody specific to extracellular TGF- $\beta 1^{22}$ (Figure $4 \mathrm{~d}$ and e). As with Western blotting, increased Smad2 phosphorylation was also seen in the $\beta 1^{\text {glo }} / \mathrm{MC}$ salivary gland using immunohistochemistry (Figure $4 \mathrm{f}$ and $\mathrm{g}$ ).

\section{Fibrosis and Acinar Cell Atrophy in $\beta 1^{\text {glo }} / \mathrm{MC}$ Mice}

The salivary glands from adult $\beta 1^{\text {glo }} / \mathrm{MC}$ mice were then examined to characterize the extent of fibrosis caused by TGF- $\beta 1$ overexpression. Masson's trichrome staining showed
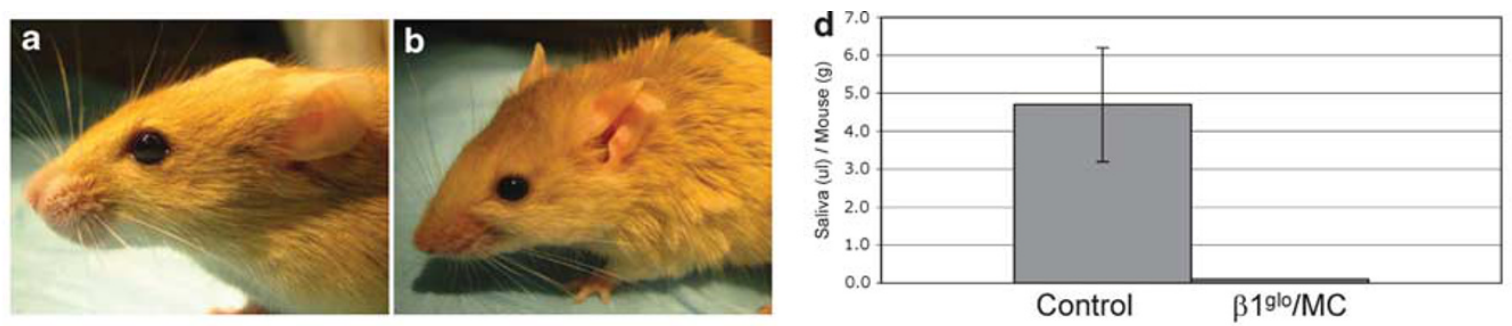

Control

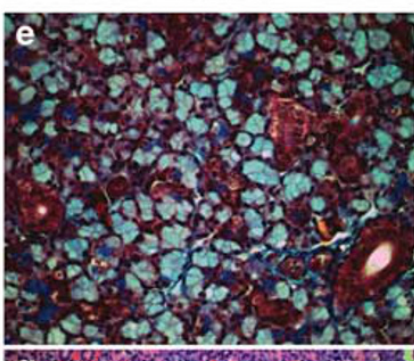

PCR

RT-PCR
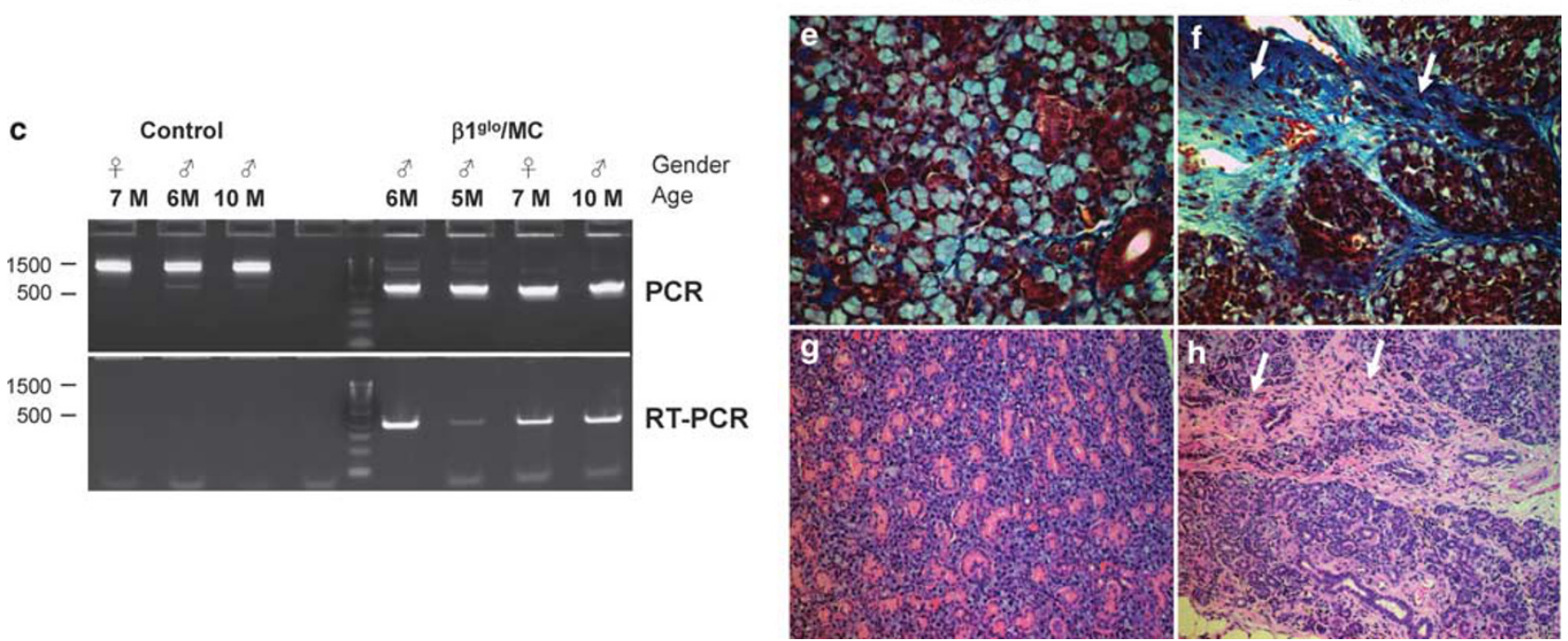

Figure 3 Adult $\beta 1^{\text {glo }} / \mathrm{MC}$ mice show acinar atrophy and fibrosis. (a and $\mathbf{b}$ ) The $\beta 1^{\text {glo }} / \mathrm{MC}$ mice $(\mathbf{b})$ are smaller than their littermates (a), with ruffled fur and deformities in the pinna of the ears. (c) PCR shows transgene recombination (top panel) and activation of TGF- $\beta 1$ expression (lower panel) only in the $\beta 1^{\text {glo }}$ / MC mice. The short 600-bp PCR product proved Cre-mediated removal of EGFP. The lower panel shows RT-PCR for the HA epitope-tagged TGF- $\beta 1$ mRNA. The gender and age of the various surviving mice is indicated above the panels. (d) Pilocarpine-induced salivation comparing five $\beta 1^{\text {glo }} / \mathrm{MC}$ mice with five littermates at 1 to 8 months of age. (e and $\mathbf{f}$ ) Masson's trichrome showing aberrant blue collagen staining in a 1-week-old male $\beta 1^{\text {glo }} / \mathrm{MC}$ submandibular gland (f) versus that in the wild-type littermate $(\mathbf{e})$. (g and $\mathbf{h}) \mathrm{H \& E}$ staining of submandibular gland sections from a 7-month-old female $\beta 1^{\text {glo }} / \mathrm{MC}$ mouse (h) and a $\beta 1^{\text {glo }}$ littermate $(\mathbf{g})$. Arrows point to areas indicative of fibrosis in the $\beta 1^{\text {glo }} / \mathrm{MC}$ mice. Magnification: $\times 40(\mathbf{e}$ and $\mathbf{f})$ and $\times 10(\mathbf{g}$ and $\mathbf{h}$ ).

Figure 2 Disrupted branching morphogenesis in newborn $\beta 1^{\text {glo }} / \mathrm{MC}$ mice. (a and $\mathbf{b}$ ) H\&E sections showing dysplastic growth of the submandibular gland in the $\beta 1^{\text {glo }} / \mathrm{MC}$ mice (b) as compared with that in the $\beta 1^{\text {glo }}$ control-line $\mathrm{c} 8$ (a). (c and $\mathbf{d}$ ) Increased Smad2 phosphorylation in the $\beta 1^{\text {glo }} / \mathrm{MC}$ submandibular gland (d) versus that in the control (c). The arrows indicate activated TGF- $\beta$ signaling particularly in the ductal cells. (e and f) AQP5staining is disorganized in the submandibular gland of the $\beta 1^{\text {glo }} / \mathrm{MC}$ mice. The arrows indicate typical AQP5 staining on the apical plasma membrane (e), which is disrupted in the $\beta 1^{\text {glo }} / \mathrm{MC}$ mice (f). Magnification: $\times 40$ and $\times 100$ (e and f). 

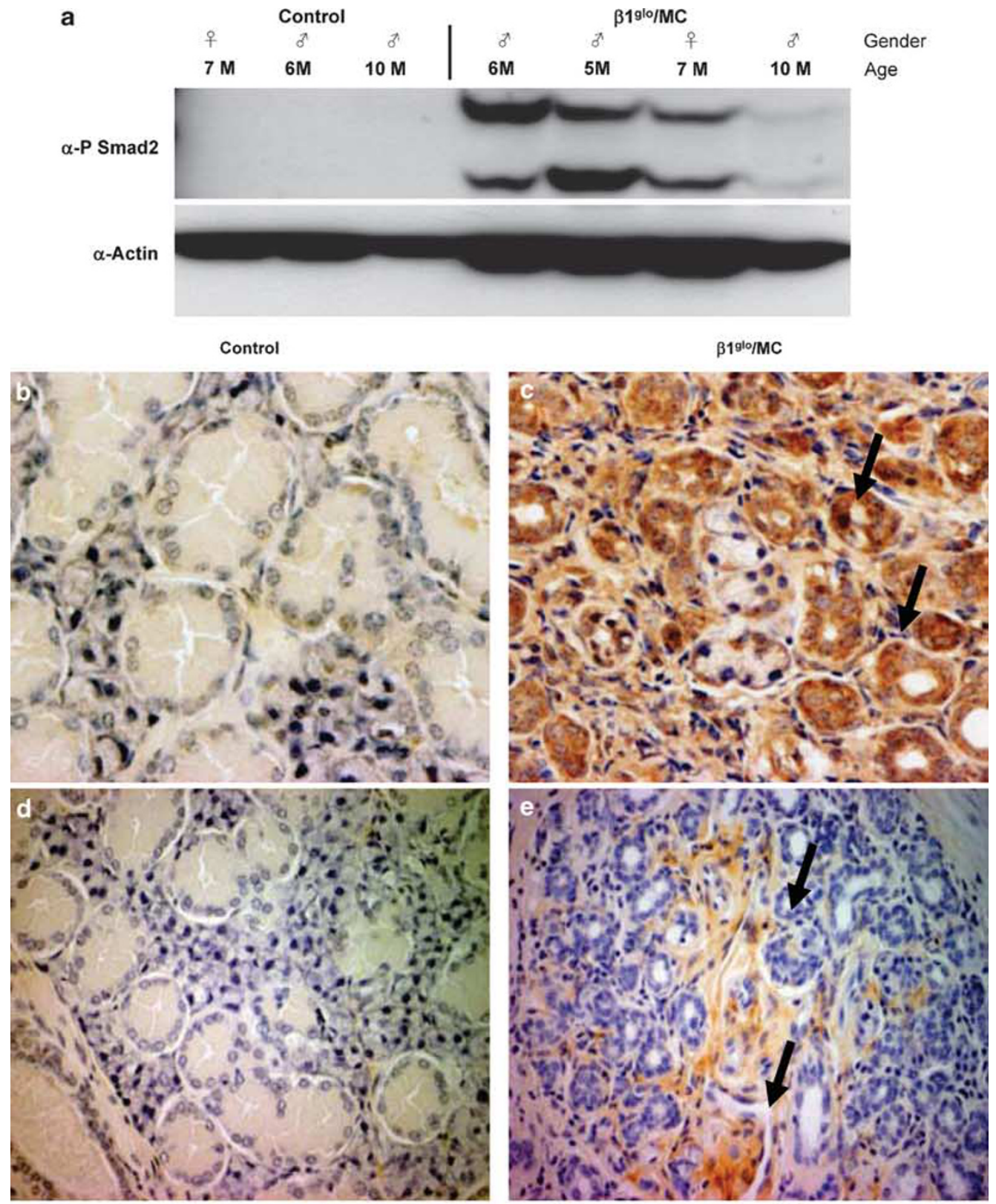

$\beta 1^{910} / \mathrm{MC}$
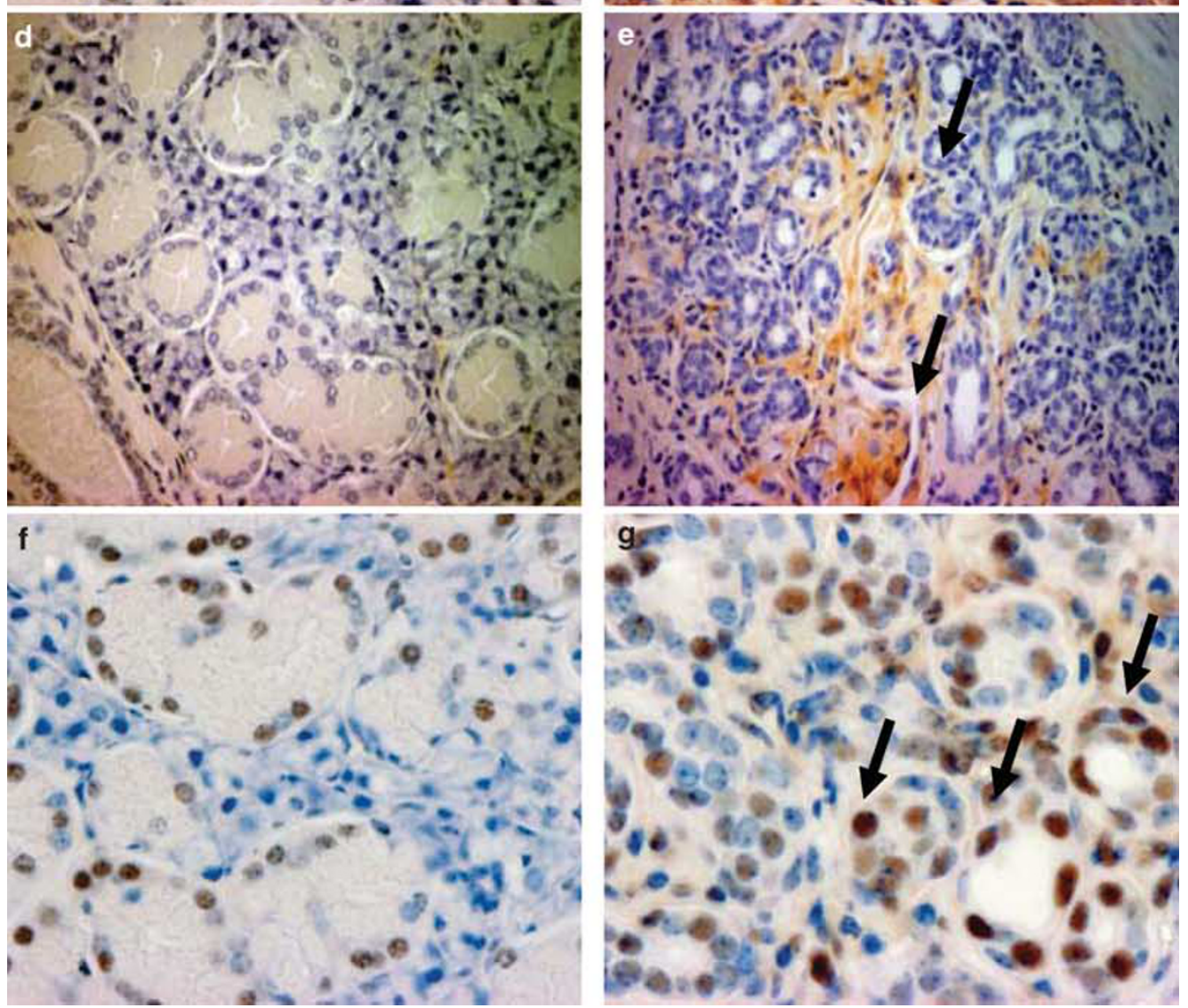
abnormal collagen deposition throughout the $\beta 1^{\text {glo }} / \mathrm{MC}$ submandibular gland (Figure $5 \mathrm{a}$ and $\mathrm{b}$ ). The blue collagen staining suggests that these glands have increased TGF- $\beta 1$ induced ECM production. ${ }^{1}$ The levels of smooth-muscle actin (Figure $5 \mathrm{c}$ and $\mathrm{d}$ ) and CTGF (Figure $5 \mathrm{e}$ and $\mathrm{f}$ ) were also elevated in the $\beta 1^{\text {glo }} / \mathrm{MC}$ salivary glands. In cases of fibrosis, TGF- $\beta 1$ often increases the expression of these proteins, ${ }^{1}$ with smooth-muscle actin being a common marker for activated myofibroblasts in fibrotic lesions. Smooth-muscle actin staining appears periductally either through recruitment of myofibroblasts by TGF- $\beta 1$ or with the induction of an epithelial-mesenchymal transition through TGF- $\beta$ signaling. ${ }^{36}$

Due to the hyposalivation and fibrosis in the $\beta 1^{\text {glo }} / \mathrm{MC}$ mice, the salivary glands were examined for histological changes in acinar cells indicative of functional abnormalities that could result from TGF- $\beta 1$ overexpression. In the salivary glands of adult $\beta 1^{\text {glo }} / \mathrm{MC}$ mice, immunostaining for the essential water channel AQP5 (Figure 6a and b) was decreased. Reduced levels of AQP5 led to decreased saliva secretion and salivary gland hypofunction. ${ }^{27,28}$ Interestingly, downregulation of AQP5 can be caused by radiation-induced injury to the salivary gland ${ }^{37,38}$ and radiation damage can led to increased TGF- $\beta 1$ expression. ${ }^{16}$ Although AQP5 also plays an important role in pulmonary secretions, the $\beta 1^{\text {glo }} / \mathrm{MC}$ mice did not show altered expression or trafficking of AQP5 in the lungs (data not shown), suggesting that the MMTV-Cre transgenic line is limiting recombination-mediated TGF- $\beta 1$ expression primarily to the salivary gland. Along with alterations in AQP5 expression, compromised salivary function also was suggested by using mucicarmine, where decreased red staining indicates reduced mucin production in the $\beta 1^{\text {glo }} / \mathrm{MC}$ mice (Figure $6 \mathrm{c}$ and $\mathrm{d}$ ).

\section{DISCUSSION}

By generating $\beta 1^{\text {glo }}$ mice and breeding them to an MMTVCre transgenic line, we set out to study the role of the overexpression of TGF- $\beta 1$ in the development of the salivary glands. TGF- $\beta 1$ regulates mucosal immunity and deletion of TGF- $\beta$ signaling in the salivary gland appears to cause an autoimmune disorder that resembles Sjögren's syndrome. ${ }^{12,39}$ Previously, we conditionally deleted T $\beta$ RI signaling in mice using MMTV-Cre. ${ }^{40}$ Whereas male mice were relatively unaffected by the conditional deletion of $\mathrm{T} \beta \mathrm{RI}$, female mice gradually developed inflammation in the salivary glands. Lack of T $\beta R I$, however, did not appear to adversely disrupt salivary gland development in the conditional knockout mice. In contrast, excess TGF- $\beta$ signaling seen herein clearly inhibits the normal growth of the salivary gland in the $\beta 1^{\text {glo }}$ / MC mice. Over-production of active TGF- $\beta 1$ ligand resulted in dysplastic growth of the submandibular glands and also disrupted branching in the glands. This likely led to the apparent increase in mesenchyme seen in the $\beta 1^{\text {glo }} / \mathrm{MC}$ mice. This phenotype is consistent with those reported in studies in which exogenous addition of TGF- $\beta 1$ was able to inhibit branching morphogenesis in the salivary glands, ${ }^{11}$ lungs, ${ }^{41}$ and mammary glands. ${ }^{35,42}$

In terms of salivary gland development, overexpression of active TGF- $\beta 1$ in the $\beta 1^{\text {glo }} / \mathrm{MC}$ mice disrupted normal organogenesis by causing decreased cell proliferation and increased mesenchyme in the developing gland. Proper ECM deposition and degradation is necessary for normal salivary gland growth ${ }^{43}$ and ECM remodeling is linked to cell proliferation within the gland. ${ }^{44}$ Both of these processes, cell proliferation and ECM deposition, are regulated by TGF- $\beta$ signaling. Interestingly, some of the developmental growth defects in the $\beta 1^{\text {glo }} / \mathrm{MC}$ mice are comparable to those seen during salivary gland development in NOD (non-obese diabetic) mice, a mouse model for Sjögren's syndrome. ${ }^{44}$ Furthermore, the changes in glandular homeostasis that occur in NOD mice appear to mimic the reported alterations in ECM turnover that are seen in patients with Sjögren's syndrome. As a principal regulator of ECM production, TGF- $\beta$ activity may potentially have a role in these observed ECM alterations. In addition to the developmental defects, impaired AQP5 trafficking seen in the $\beta 1^{\text {glo }} / \mathrm{MC}$ mice is likewise present in Sjögren's syndrome patients ${ }^{45}$ as well as in the NOD mouse model. ${ }^{46,47}$ AQP5 is normally located in the luminal membranes of the acinar cells of the submandibular gland and is essential for saliva secretion, but expression of AQP5 was mislocalized and reduced in the $\beta 1^{\text {glo }} / \mathrm{MC}$ mice. In this mouse model, at least, the effects of excess TGF- $\beta$ signaling in the developing salivary gland probably leads to inhibited proliferation and dysplastic growth of the acinar cells, thereby indirectly resulting in a reduced and altered expression pattern for AQP5. This, in turn, may possibly contribute to the early salivary gland hypofunction seen in the $\beta 1^{\text {glo }} / \mathrm{MC}$ mice. At later time points, much of the normal salivary gland parenchyma is replaced with fibrous tissue.

In the $\beta 1^{\text {glo }} / \mathrm{MC}$ mice, overexpression of TGF- $\beta 1$ caused fibrosis of the salivary glands, which was accompanied by atrophy of the GCDs and the acini. Overexpression of active TGF- $\beta 1$ resulted in excessive deposition of ECM proteins that appeared to severely affect the ability of the $\beta 1^{\text {glo }} / \mathrm{MC}$ mice to secrete saliva. Except for the dilated ducts within the $\beta 1^{\text {glo }} / \mathrm{MC}$ salivary gland, most of the normal glandular

Figure 4 Recombination-mediated activation of TGF- $\beta 1$ in adult $\beta 1^{\text {glo }} / \mathrm{MC}$ mice. (a) A Western blot showing Smad 2 phosphorylation in the salivary glands of the $\beta 1^{\text {glo }} / \mathrm{MC}$ mice. (b, c) Compared with the control (b), increased TGF- $\beta 1$ staining is seen in the submandibular gland of a 10-month-old male $\beta 1^{\text {glo }} / \mathrm{MC}$ mouse (c). Arrows indicate TGF- $\beta 1$ staining in the ductal cells. (d and e) Although little staining is seen in the control (d), extracellular TGF- $\beta 1$ is seen amid the ducts of the $\beta 1^{\text {glo }} / \mathrm{MC}$ salivary gland, as indicated by the arrows (e). ( $\mathbf{f}$ and $\mathbf{g}$ ) When compared with a healthy control gland (f), more intense staining of phosphorylated Smad 2 is seen in the $\beta 1^{\text {glo }} / \mathrm{MC}$ mice $(\mathbf{g})$. Increased nuclear localization of phosphorylated Smad 2 in the $\beta 1^{\text {glo }} / \mathrm{MC}$ mice is indicated by arrows. Magnification: $\times 40$. 


\section{Control}
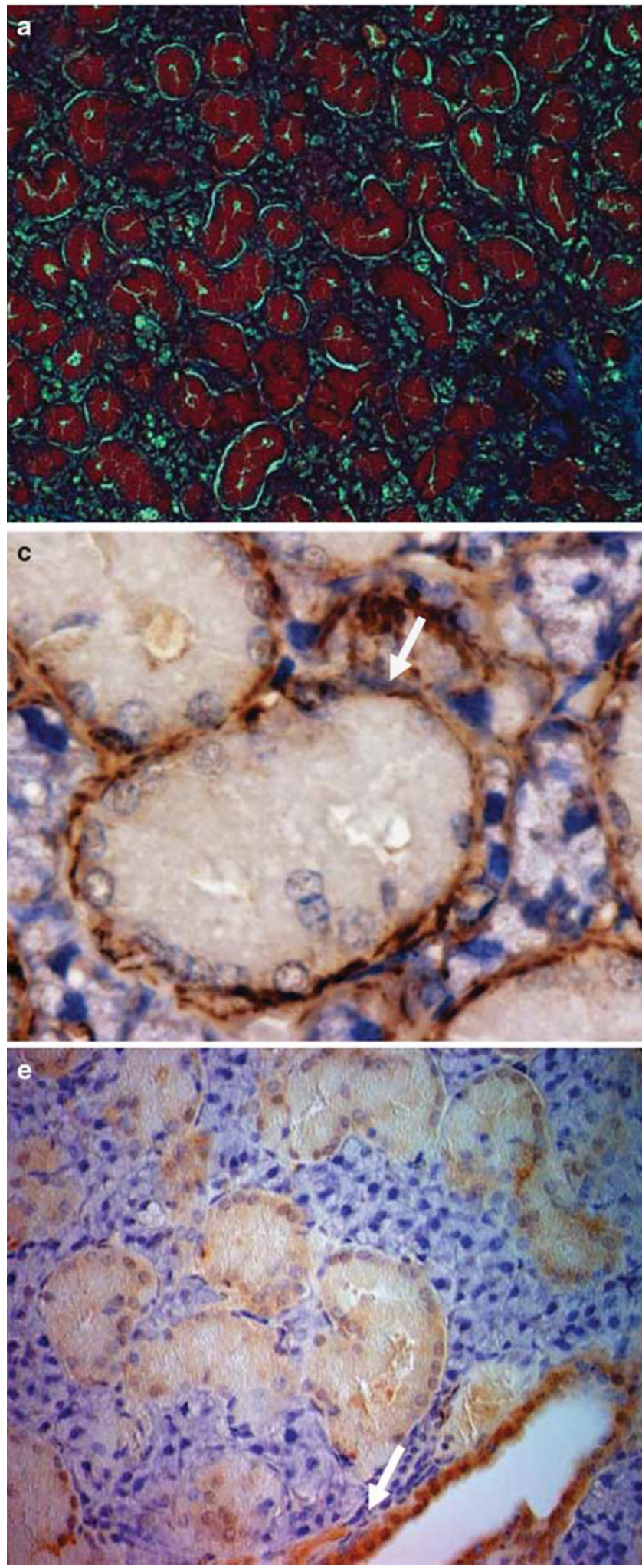

$\beta 1$ glo/MC
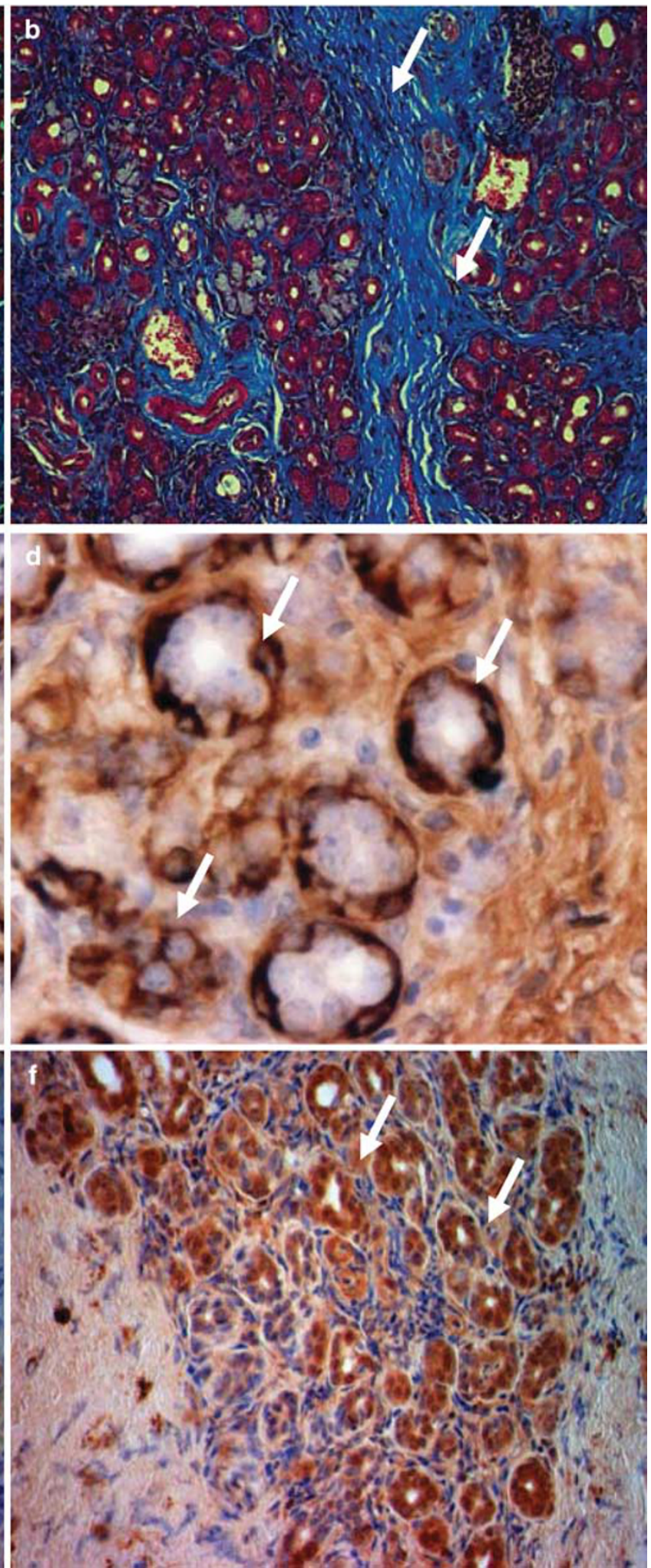

Figure 5 Immunostaining for markers of fibrosis. (a and $\mathbf{b})$ When compared with the control (a), intense blue collagen fibrils are seen in the $\beta 1^{\text {glo }} / \mathrm{MC}$ gland (b) using Masson's trichrome stain. (c and $\mathbf{d}$ ) The arrows indicate altered staining pattern for anti-smooth-muscle actin, a marker for activated myofibroblasts, between the wild-type (c) and the $\beta 1^{\text {glo }} / \mathrm{MC}$ gland (d). (e and $\mathbf{f}$ ) In contrast to healthy mouse (e), overexpression of TGF- $\beta 1$ induced CTGF expression in the submandibular gland of the $\beta 1^{\text {glo }} / \mathrm{MC}$ mice (f). 

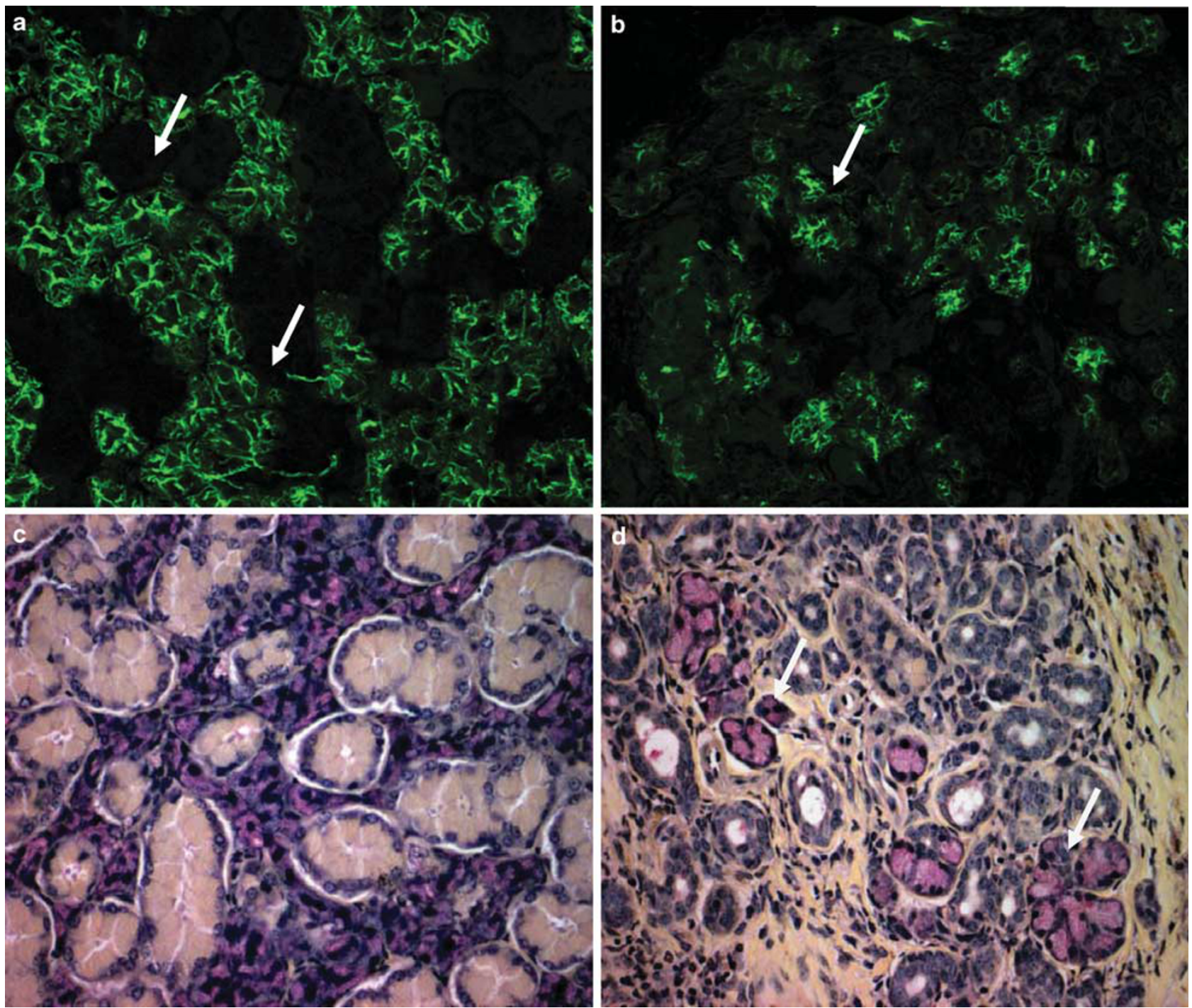

Figure 6 Immunochemical staining to examine potential salivary gland function in adult mice. (a and $\mathbf{b})$ The arrows indicate more AQP5 staining in a 6-month-old male control littermate (a) when compared with that in the $\beta 1^{\text {glo }} / \mathrm{MC}$ mouse (b). (c and d) Mucicarmine staining of the salivary gland of a 10-month-old wild-type mouse (c) as compared with the staining of a $\beta 1^{\text {glo }} / \mathrm{MC}$ mouse gland (d). The red staining, indicative of epithelial mucin, is less intense in the $\beta 1^{\text {glo }} / \mathrm{MC}$ submandibular gland. Magnification: $\mathbf{a}-\mathbf{d} \times 20$.

parenchyma was replaced with fibrotic tissue and this most likely caused the lack of saliva secretion in the adult mice. However, TGF- $\beta 1$ could have concurrently affected saliva secretion by functioning as a negative regulator of growth and by inhibiting the activity of the $\mathrm{Na}^{+} / \mathrm{K}^{+}$ATPase. ${ }^{48}$ The principal hallmarks of TGF- $\beta$-induced fibrosis were seen in the salivary glands of the $\beta 1^{\text {glo }} / \mathrm{MC}$ mice. ECM proteins and other indicators of fibrosis such as CTGF and smooth-muscle actin were upregulated in response to the transgenic expression of TGF- $\beta$. While acinar atrophy reduced the overall size of the salivary glands in our $\beta 1^{\text {glo }} / \mathrm{MC}$ mice, we were still able to study the effect of excess production of TGF- $\beta 1$ on pathological glandular fibrosis. In humans, increased fibrosis of the salivary glands is seen in geriatric patients, ${ }^{14}$ although it is limited and does not affect salivation significantly among healthy elders. ${ }^{49}$

The pathology seen in the $\beta 1^{\text {glo }} / \mathrm{MC}$ mice is similar to submandibular gland atrophy, which can be caused by ligation of the salivary gland in animal models or in certain cases of salivary adenitis seen in patients. ${ }^{50,51}$ Obstruction of the salivary gland in these cases often leads to fibrosis, degeneration of acinar cells, and dilation of the ducts. Additionally, many patients with Sjögren's syndrome develop progressive fibrosis in their salivary glands, ${ }^{52-54}$ although analysis of TGF- $\beta$ production in Sjögren's syndrome has yielded conflicting results. ${ }^{12,40,55,56}$ Typically, fibrosis occurs when repeated injury, such as chronic inflammation, triggers sustained production of TGF- $\beta$ because of unresolved tissue damage. ${ }^{57-60}$ 
Radiotherapy for head-and-neck cancer can also cause fibrosis of the submandibular gland accompanied by a high density of small-dilated ducts ${ }^{15}$ and TGF- $\beta 1$ can be induced by radiation. ${ }^{16}$ Such extensive salivary gland fibrosis results in diminished saliva production, which leads to numerous morbidities in patients, including dysphagia, increased oral infections (eg, Candidiasis, dental caries), as well as generalized oral discomfort. Radiation additionally causes downregulation of AQP5 expression in the salivary glands of rats and mice, with reductions in AQP5 staining similar to those we have noted here using the $\beta 1^{\text {glo }} / \mathrm{MC}$ mice. ${ }^{37,38}$ The $\beta 1^{\text {glo }} / \mathrm{MC}$ mice, therefore, seem to mimic the process of salivary gland fibrosis seen under pathological conditions such as radiation-induced injury and may be a useful model to investigate early interventions to treat fibrosis.

In conclusion, changes in the expression levels of TGF- $\beta$ can have a profound effect on the physiology of the salivary gland. Lack of TGF- $\beta$ signaling in the salivary gland appears to trigger autoimmunity. ${ }^{12,39,40}$ In contrast, excess TGF- $\beta$ results in the replacement of the normal salivary gland parenchyma with connective tissue. Therefore, proper balance of TGF- $\beta$ expression and signaling appears necessary for normal salivary gland homeostasis.

\section{ACKNOWLEDGEMENTS}

We thank Drs Matthew Hoffman, Wan-Jun Chen, and Nancy Francis for critically reading the paper, and Drs Ana Cotrim, Thomas Bugge, Alfredo Molinolo and Robert Redman for helpful discussions. We also thank Drs John Letterio and Andrzej Dlugosz for the gift of active hemagglutinin epitope-tagged TGF- $\beta 1$ CDNA and PCLE vector, respectively. These studies were supported by the Division of Intramural Research, National Institute of Dental and Craniofacial Research, National Eye Institute, National Cancer Institute, Division of Veterinary Resources, The National Institutes of Health.

\section{DISCLOSURE/CONFLICT OF INTEREST}

The authors declare no conflict of interest.

1. Ignotz RA, Massague J. Transforming growth factor-beta stimulates the expression of fibronectin and collagen and their incorporation into the extracellular matrix. J Biol Chem 1986;261:4337-4345.

2. Leask $A$, Abraham DJ. TGF-beta signaling and the fibrotic response. FASEB J 2004;18:816-827.

3. Zavadil J, Böttinger EP. TGF-beta and epithelial-to-mesenchymal transitions. Oncogene 2005;24:5764-5774.

4. Kalluri R, Neilson EG. Epithelial-mesenchymal transition and its implications for fibrosis. J Clin Invest 2003;112:1776-1784.

5. Lee KY, Bae SC. TGF-beta-dependent cell growth arrest and apoptosis. J Biochem Mol Biol 2002;35:47-53.

6. Pepper MS. Transforming growth factor-beta: vasculogenesis, angiogenesis, and vessel wall integrity. Cytokine Growth Factor Rev 1997;8:21-43.

7. Li MO, Wan YY, Sanjabi S, et al. Transforming growth factor-beta regulation of immune responses. Annu Rev Immunol 2006;24:99-146.

8. Jaskoll $T$, Melnick M. Submandibular gland morphogenesis: stagespecific expression of TGF-alpha/EGF, IGF, TGF-beta, TNF, and IL-6 signal transduction in normal embryonic mice and the phenotypic effects of TGF-beta2, TGF-beta3, and EGF-r null mutations. Anat Rec 1999;256:252-268.

9. Lourenço SV, Uyekita SH, Lima DM, et al. Developing human minor salivary glands: morphological parallel relation between the expression of TGF-beta isoforms and cytoskeletal markers of glandular maturation. Virchows Arch 2008;452:427-434.
10. Lehnert SA, Akhurst RJ. Embryonic expression pattern of TGF beta type-1 RNA suggests both paracrine and autocrine mechanisms of action. Development 1988;104:263-273.

11. Hardman P, Landels E, Woolf AS, et al. TGF-beta1 inhibits growth and branching morphogenesis in embryonic mouse submandibular and sublingual glands in vitro. Dev Growth Differ 1994;36:567-577.

12. Kizu $\mathrm{Y}$, Sakurai $\mathrm{H}$, Katagiri $\mathrm{S}$, et al. Immunohistological analysis of tumour growth factor beta 1 expression in normal and inflamed salivary glands. J Clin Pathol 1996;49:728-732.

13. Amano O, Tsuji T, Nakamura T, et al. Expression of transforming growth factor beta 1 in the submandibular gland of the rat. J Histochem Cytochem 1991;39:1707-1711.

14. Ficarra BJ. Submandibular salivary gland fibrosis. J Med 1996;27: 103-113.

15. Cooper JS, Fu K, Marks J, et al. Late effects of radiation therapy in the head and neck region. Int J Radiat Oncol Biol Phys 1995;31:1141-1164.

16. Martin M, Lefaix J, Delanian S. TGF-beta1 and radiation fibrosis: a master switch and a specific therapeutic target? Int J Radiat Oncol Biol Phys 2000;47:277-290.

17. Wagner KU, McAllister K, Ward T, et al. Spatial and temporal expression of the Cre gene under the control of the MMTV-LTR in different lines of transgenic mice. Transgenic Res 2001;10:545-553.

18. Wolfraim LA, Alkemade GM, Alex B, et al. Development and application of fully functional epitope-tagged forms of transforming growth factor-beta. J Immunol Methods 2002;266:7-18.

19. Bradley SV, Hyun TS, Oravecz-Wilson Kl, et al. Degenerative phenotypes caused by the combined deficiency of murine HIP1 and HIP1r are rescued by human HIP1. Hum Mol Genet 2007;16:1279-1292.

20. Samuel SK, Hurta RA, Kondaiah P, et al. Autocrine induction of tumor protease production and invasion by a metallothionein-regulated TGF-beta 1 (Ser223, 225). EMBO J 1992;11:1599-1605.

21. Sauer B, Henderson N. Targeted insertion of exogenous DNA into the eukaryotic genome by the Cre recombinase. New Biol 1990;2:441-449.

22. Flanders KC, Thompson NL, Cissel DS, et al. Transforming growth factor-beta 1: histochemical localization with antibodies to different epitopes. J Cell Biol 1989;108:653-660.

23. Wellner RB, Hong $\mathrm{S}$, Cotrim $\mathrm{AP}$, et al. Modifying the $\mathrm{NH} 2$ and $\mathrm{COOH}$ termini of aquaporin-5: effects on localization in polarized epithelial cells. Tissue Eng 2005;11:1449-1458.

24. Sauer B, Henderson N. Site-specific DNA recombination in mammalian cells by the Cre recombinase of bacteriophage P1. Proc Natl Acad Sci USA 1988;85:5166-5170.

25. Lakso M, Sauer B, Mosinger Jr B, et al. Targeted oncogene activation by site-specific recombination in transgenic mice. Proc Natl Acad Sci USA 1992;89:6232-6236.

26. Willimsky G, Blankenstein T. Sporadic immunogenic tumours avoid destruction by inducing T-cell tolerance. Nature 2005;437:141-146.

27. Wagner KU, Wall RJ, St-Onge L, et al. Cre-mediated gene deletion in the mammary gland. Nucleic Acids Res 1997;25:4323-4330.

28. Ewald D, Li M, Efrat $S$, et al. Time-sensitive reversal of hyperplasia in transgenic mice expressing SV40 T antigen. Science 1996;273:13841386.

29. Ma T, Song $Y$, Gillespie A, et al. Defective secretion of saliva in transgenic mice lacking aquaporin-5 water channels. J Biol Chem 1999;274:20071-20074.

30. Krane CM, Melvin JE, Nguyen HV, et al. Salivary acinar cells from aquaporin 5-deficient mice have decreased membrane water permeability and altered cell volume regulation. J Biol Chem 2001;276:23413-23420.

31. Delporte C, Steinfeld S. Distribution and roles of aquaporins in salivary glands. Biochim Biophys Acta 2006;1758:1061-1070.

32. He $X$, Tse CM, Donowitz $M$, et al. Polarized distribution of key membrane transport proteins in the rat submandibular gland. Pflugers Arch 1997;433:260-268.

33. Qiao W, Li AG, Owens $P$, et al. Hair follicle defects and squamous cell carcinoma formation in Smad4 conditional knockout mouse skin. Oncogene 2006;25:207-217.

34. Sellheyer K, Bickenbach JR, Rothnagel JA, et al. Inhibition of skin development by overexpression of transforming growth factor beta 1 in the epidermis of transgenic mice. Proc Natl Acad Sci USA 1993;90:5237-5241.

35. Pierce Jr DF, Johnson MD, Matsui $Y$, et al. Inhibition of mammary duct development but not alveolar outgrowth during pregnancy in 
transgenic mice expressing active TGF-beta 1. Genes Dev 1993;7: 2308-2317.

36. Guarino M, Tosoni A, Nebuloni M. Direct contribution of epithelium to organ fibrosis: epithelial-mesenchymal transition. Hum Pathol 2009;40:1365-1376.

37. Li Z, Zhao D, Gong B, et al. Decreased saliva secretion and downregulation of AQP5 in submandibular gland in irradiated rats. Radiat Res 2006;165:678-687.

38. Takakura K, Takaki S, Takeda I, et al. Effect of cevimeline on radiationinduced salivary gland dysfunction and AQP5 in submandibular gland in mice. Bull Tokyo Dent Coll 2007;48:47-56.

39. McCartney-Francis NL, Mizel DE, Redman RS, et al. Autoimmune Sjögren's-like lesions in salivary glands of TGF-beta1-deficient mice are inhibited by adhesion-blocking peptides. J Immunol 1996;157: 1306-1312.

40. Nandula SR, Amarnath S, Molinolo A, et al. Female mice are more susceptible to developing inflammatory disorders due to impaired transforming growth factor beta signaling in salivary glands. Arthritis Rheum 2007;56:1798-1805.

41. Serra R, Pelton RW, Moses HL. TGF beta 1 inhibits branching morphogenesis and $\mathrm{N}$-myc expression in lung bud organ cultures. Development 1994;120:2153-2161.

42. Robinson $S D$, Silberstein $G B$, Roberts $A B$, et al. Regulated expression and growth inhibitory effects of transforming growth factor-beta isoforms in mouse mammary gland development. Development 1991;113:867-878.

43. Hardman P, Spooner BS. Localization of extracellular matrix components in developing mouse salivary glands by confocal microscopy. Anat Rec 1992;234:452-459.

44. Cha S, van Blockland SC, Versnel MA, et al. Abnormal organogenesis in salivary gland development may initiate adult onset of autoimmune exocrinopathy. Exp Clin Immunogenet 2001;18:143-160.

45. Steinfeld S, Cogan E, King LS, et al. Abnormal distribution of aquaporin-5 water channel protein in salivary glands from Sjögren's syndrome patients. Lab Invest 2001;81:143-148.

46. Konttinen $\mathrm{YT}$, Tensing EK, Laine $\mathrm{M}$, et al. Abnormal distribution of aquaporin-5 in salivary glands in the NOD mouse model for Sjögren's syndrome. J Rheumatol 2005;32:1071-1075.
47. Soyfoo MS, De Vriese C, Debaix $\mathrm{H}$, et al. Modified aquaporin 5 expression and distribution in submandibular glands from NOD mice displaying autoimmune exocrinopathy. Arthritis Rheum 2007;56:2566-2574.

48. Streckfus C, Bigler L, O'Bryan T. Aging and salivary cytokine concentrations as predictors of whole saliva flow rates among women: a preliminary study. Gerontology 2002;48:282-288.

49. Baum BJ, Ship JA, Wu AJ. Salivary gland function and aging: a model for studying the interaction of aging and systemic disease. Crit Rev Oral Biol Med 1992;4:53-64.

50. Bhaskar SN, Bolden TE, Weinmann JP. Experimental obstructive adenitis in the mouse. J Dent Res 1956:35:852-862.

51. Teymoortash A, Tiemann M, Schrader C, et al. Transforming growth factor beta in chronic obstructive sialadenitis of human submandibular gland. Arch Oral Biol 2003;48:111-116.

52. Koski H, Konttinen $\mathrm{YT}$, Gu XH, et al. Transforming growth factor beta 2 in labial salivary glands in Sjögren's syndrome. Ann Rheum Dis 1995;54:744-747.

53. Skopouli FN, Li L, Boumba D, et al. Association of mast cells with fibrosis and fatty infiltration in the minor salivary glands of patients with Sjögren's syndrome. Clin Exp Rheumatol 1998;16:63-65.

54. Koski $\mathrm{H}$, Janin A, Humphreys-Beher MG, et al. Tumor necrosis factor-alpha and receptors for it in labial salivary glands in Sjögren's syndrome. Clin Exp Rheumatol 2001;19:131-137.

55. Cauli A, Yanni G, Pitzalis C, et al. Cytokine and adhesion molecule expression in the minor salivary glands of patients with Sjögren's syndrome and chronic sialoadenitis. Ann Rheum Dis 1995:54:209-215.

56. Mason Gl, Hamburger J, Bowman S, et al. Salivary gland expression of transforming growth factor beta isoforms in Sjogren's syndrome and benign lymphoepithelial lesions. Mol Pathol 2003;56:52-59.

57. Border WA, Noble NA. Transforming growth factor beta in tissue fibrosis. N Engl J Med 1994;331:1286-1292.

58. Border WA, Ruoslahti E. Transforming growth factor-beta in disease: the dark side of tissue repair. J Clin Invest 1992;90:1-7.

59. Letterio JJ, Roberts AB. Regulation of immune responses by TGF-beta. Annu Rev Immunol 1998;16:137-161.

60. Wahl SM. Transforming growth factor-beta: innately bipolar. Curr Opin Immunol 2007;19:55-62. 